\title{
Hemoglobin A1c Level Is Not Related to the Severity of Atherosclerosis in Patients with Acute Coronary Syndrome
}

\author{
Xinhong Wang, Zhenhua Han, Guanghua Hao, Yongqin Li, Xin Dong, and Congxia Wang \\ Department of Cardiovascular Medicine, Second Affiliated Hospital of Medical College, Xian Jiaotong University, \\ Xian, Shaanxi 710004, China \\ Correspondence should be addressed to Zhenhua Han; drhanzhenhua029@163.com
}

Received 12 May 2015; Accepted 8 July 2015

Academic Editor: Giuseppe Murdaca

Copyright (C) 2015 Xinhong Wang et al. This is an open access article distributed under the Creative Commons Attribution License, which permits unrestricted use, distribution, and reproduction in any medium, provided the original work is properly cited.

Background. The relationship between hemoglobin Alc (HbAlc) levels and the extent of coronary artery stenosis in patients with acute coronary syndrome (ACS) remains uncertain. The present study aimed to assess the correlation of HbAlc level with angiographic coronary atherosclerosis. Methods. 292 consecutive ACS patients were enrolled and stratified into three groups according to HbAlc levels (group 1: $<6.0 \%, n=137$; group 2: $6.0-6.4 \%, n=67$; group 3: $\geq 6.5 \%, n=88$ ). The severity of coronary arteriosclerosis was assessed by Gensini score. The relationship between HbAlc and Gensini score was analyzed by multiple variables analysis. Results. HbAlc level was not associated with the severity of CAD assessed by Gensini score in patients with ACS, even after the adjustment for other risk factors. However, NT-proBNP, ApoAl and LVEF levels were independent predictors for CAD severity. Moreover, HbAlc level was not associated with the risk of high Gensini score (>40) by logistic regression analysis. Diabetes mellitus (DM) and LVEF levels were two independent risk factors for high Gensini score. Conclusions. HbAlc level is not a significant and independent marker for the severity of angiography in ACS patients, even in high-risk patients.

\section{Introduction}

Acute coronary syndrome (ACS) indicates serious clinical manifestation of coronary artery disease (CAD) and is the major cause of morbidity and mortality worldwide. The severity of coronary atherosclerosis is closely associated with cardiovascular prognosis in patients with ACS [1]. Consequently, prediction and diagnosis of the extent of coronary lesion in ACS are important for clinical management of this disease.

Haemoglobin (HbAlc) concentration is an established marker of average blood glucose concentration and has been suggested as a diagnostic or screening tool for diabetes [2]. Elevated HbAlc levels in patients with or without diabetes mellitus (DM) are associated with an increased risk for cardiovascular disease and mortality [3, 4]. A communitybased population study including 11,092 patients without DM found that elevated HbAlc level was strongly associated with the risks of cardiovascular disease and mortality [4]. Timmer et al. demonstrated that elevated $\mathrm{HbAlc}$ level was associated with adverse outcome in nondiabetic patients with ST-segment-elevation myocardial infarction (STEMI) [5].
On the other hand, an increase of $1 \%$ in HbAlc concentration was associated with roughly a $30 \%$ increase in all cause and $40 \%$ increase in cardiovascular or ischaemic heart disease mortality among individuals with diabetes [6]. However, the prognostic role of $\mathrm{HbAlc}$ in the acute phase in patients with STEMI is not clear [7]. A recent study reported that there was no overall association between HbAlc level and the prognosis of nondiabetic patients with suspected stable angina pectoris (SAP) [8]. However, another study found that $\mathrm{HbAlc}$ appeared to be an independent predictor for the severity of CAD and poor outcome in patients with stable angina [9].

To the best of our knowledge, the relationship between HbAlc level and the extent of coronary artery stenosis in patients with ACS remains uncertain. Therefore, this study aimed to assess the relationship of HbAlc level with the extent of angiographic coronary atherosclerosis.

\section{Methods}

2.1. Patients. The study recruited 292 consecutive ACS patients admitted to Cardiology Department of the Second 
Affiliated Hospital of Medical College of Xi'an Jiaotong University from January 2012 to July 2014. All patients, including unstable angina, non-ST-segment-elevation myocardial infarction, and ST-segment-elevation MI, met the ACS diagnostic criteria outlined in the ACC/AHA 2007 guidelines. Exclusion criteria included advanced liver or renal dysfunction, coronary bypass surgery, cancer, active or chronic inflammatory or autoimmune diseases, acute infection, and hematological diseases. Informed written consent was obtained from all patients, and the study complied with the Declaration of Helsinki and was approved by the Ethics Committee of our hospital. Cardiovascular risk factors and cardiovascular medications were recorded by standardized questionnaire. The left ventricular ejection fraction (LVEF) was evaluated by echocardiograph.

2.2. Laboratory Tests. Peripheral blood samples were drawn routinely from patients in a fasting state. Plasma concentrations of glucose, lipids, lipoproteins, and other biochemical parameters were determined at the Biochemistry Department in our hospital. High-sensitivity C-reactive protein (hsCRP) level was analyzed by a highly sensitive ABC-double-antibody sandwich ELISA (R\&D). HbAlc level was determined using cation exchange column chromatography on an automated HPLC instrument (Variant II Turbo, Bio-Rad Laboratories, Hercules, California, USA). NT-proBNP was measured using electrochemiluminescencebased immunoanalytical system (Roche Diagnostics Ltd., Mannheim, Germany).

2.3. Coronary Angiography. Coronary angiography was analyzed by two independent experienced cardiologists. CAD was defined as any main branch with coronary artery stenosis $\geq 50 \%$. The burden of coronary arteriosclerosis was assessed by Gensini score system [10]. Reductions in lumen diameter of $25 \%, 50 \%, 75 \%, 90 \%, 99 \%$, and complete occlusion were evaluated as $1,2,4,8,16$, and 32 , respectively. The stenosis score was multiplied by a factor taking into account the position of the coronary lesions: 5 for the left main coronary artery, 2.5 for the proximal left anterior descending artery or proximal left circumflex artery, 1.5 for the mid-region of the left anterior descending artery, 1 for the distal left anterior descending artery, the mid-distal region of the left circumflex artery or right coronary artery, and 0.5 for other segments.

2.4. Statistical Analysis. All statistical analyses were performed using the SPSS software package version 18.0 (SPSS Inc., Chicago, IL, USA). Quantitative variables were expressed as means \pm standard deviation and categorical variables as frequency and percentage. The Shapiro-Wilk test was performed to assess normal distribution of quantitative variables. Nonnormally distributed variables such as NT-proBNP and hsCRP were log-transformed. Analysis of variance (ANOVA), $t$-test, or chi-square test was used for the comparisons of the groups. A multiple linear regression model was used to assess the association between HbAlc and Gensini score. A binary logistic regression model using stepwise selection process for the prediction of high-risk

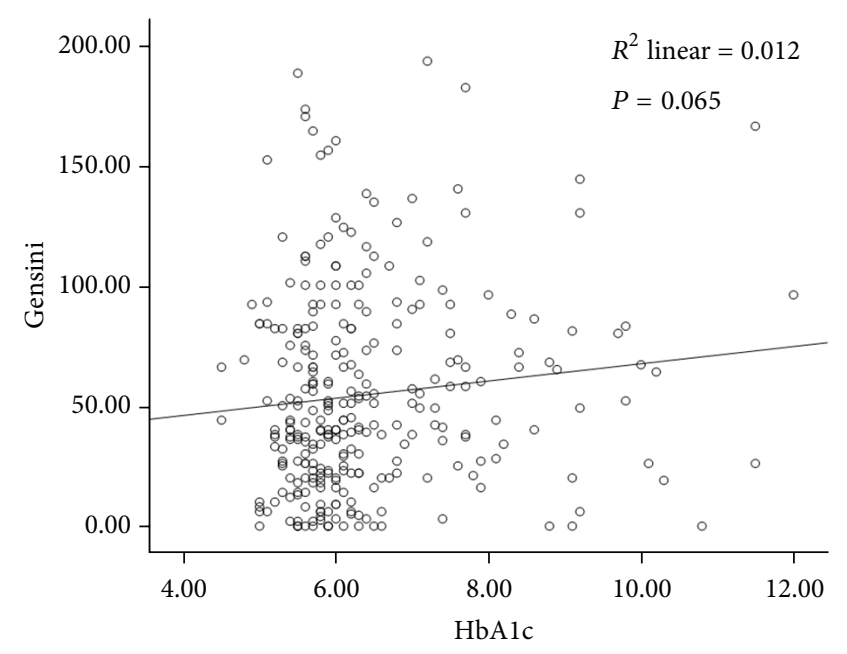

Figure 1: Correlation between HbAlc level and Gensini score in patients with ACS.

coronary lesions (Gensini score $>40$ ) was calculated. A 2tailed $P<0.05$ was considered statistically significant.

\section{Results}

3.1. Baseline Characteristics of Patients. The demographic and clinical characteristics of patients in different groups according to HbAlc levels were shown in Table 1. No difference in Gensini score was found in different groups $(P=0.085)$. Intergroup comparisons showed that patients with higher HbAlc level had higher fasting blood glucose and hsCRP levels. The frequency distribution of older subjects differed significantly in three groups. There were no significant differences in other characteristics among the three groups.

3.2. Association of HbAlc Level with Coronary Atherosclerosis. To explore the association of the extent of coronary angiographic results with $\mathrm{HbAlc}$ level, a multiple linear regression analysis using stepwise selection process was performed to adjust for the variables which are likely to be independently associated with Gensini score. Age, gender, smoking, ventricular function, NT-proBNP, ApoA1, heart rate, HDL-C, fasting blood glucose, and hsCRP were adjusted. No correlation was found between HbAlc level and the extent of coronary atherosclerosis in ACS, as determined with the Gensini score ( $\beta=0.079, P=0.224)$. Both fasting blood glucose and hsCRP levels showed no association with the Gensini score. The relationship between HbAlc level and the Gensini score in patients with ACS was shown in Figure 1. However, we found that NT-proBNP, LVEF, ApoA1, and HDL-C levels were independent predictors of Gensini score (Table 2).

3.3. Correlation between HbA1c Level and High Gensini Score. To further explore the association of HbAlc level with high Gensini score $(>40)$, a binary logistic regression analysis using stepwise selection process was applied for determining the predictors of high Gensini score. Variables in this model 
TABLE 1: Baseline clinical characteristics according to HbAlc level.

\begin{tabular}{|c|c|c|c|c|}
\hline \multirow{2}{*}{ Variables } & \multicolumn{3}{|c|}{ HbAlc } & \multirow{2}{*}{$P$} \\
\hline & $1(<6.0 \%)$ & $2(6.0 \sim 6.4 \%)$ & $3(\geq 6.5 \%)$ & \\
\hline Age (years) & $57.19 \pm 12.33$ & $62.66 \pm 10.17$ & $62.08 \pm 12.21$ & $<0.001$ \\
\hline Male, $n(\%)$ & $106(0.77)$ & $54(0.81)$ & $59(0.67)$ & 0.110 \\
\hline Hypertension, $n(\%)$ & $63(0.46)$ & $33(0.49)$ & $31(0.35)$ & 0.160 \\
\hline $\mathrm{DM}, n(\%)$ & $6(0.04)$ & $7(0.10)$ & $61(0.71)$ & $<0.001$ \\
\hline Smoking, $n(\%)$ & $77(0.56)$ & $43(0.64)$ & $41(0.47)$ & 0.090 \\
\hline Previous MI, $n(\%)$ & $15(0.11)$ & $7(0.10)$ & $6(0.07)$ & 0.570 \\
\hline Previous PCI, $n(\%)$ & $11(0.08)$ & $7(0.10)$ & $7(0.08)$ & 0.821 \\
\hline SBP (mmHg) & $128.23 \pm 22.98$ & $125.39 \pm 25.89$ & $129.45 \pm 21.76$ & 0.551 \\
\hline DBP (mmHg) & $79.32 \pm 14.54$ & $78.91 \pm 16.18$ & $79.23 \pm 11.63$ & 0.981 \\
\hline HR (bpm) & $74.74 \pm 13.37$ & $73.94 \pm 14.52$ & $74.03 \pm 15.35$ & 0.905 \\
\hline LVEF (\%) & $60.67 \pm 11.00$ & $58.29 \pm 13.65$ & $57.09 \pm 12.41$ & 0.095 \\
\hline $\mathrm{TC}(\mathrm{mmol} / \mathrm{L})$ & $3.83 \pm 0.98$ & $3.96 \pm 0.99$ & $3.80 \pm 0.90$ & 0.566 \\
\hline TG (mmol/L) & $1.66 \pm 1.08$ & $1.54 \pm 0.83$ & $1.81 \pm 1.15$ & 0.283 \\
\hline HDL-C (mmol/L) & $0.92 \pm 0.21$ & $0.95 \pm 0.24$ & $0.87 \pm 0.21$ & 0.080 \\
\hline LDL-C (mmol/L) & $2.29 \pm 0.87$ & $2.37 \pm 0.93$ & $2.26 \pm 0.75$ & 0.709 \\
\hline ApoA1 (g/L) & $1.07 \pm 0.17$ & $1.09 \pm 0.19$ & $1.06 \pm 0.19$ & 0.558 \\
\hline ApoB (g/L) & $0.76 \pm 0.23$ & $0.79 \pm 0.22$ & $0.78 \pm 0.20$ & 0.634 \\
\hline $\mathrm{Lp}(\mathrm{a})(\mathrm{mg} / \mathrm{L})$ & $189.87 \pm 141.33$ & $268.17 \pm 256.97$ & $200.46 \pm 162.24$ & $<0.05$ \\
\hline FBS (mmol/L) & $6.03 \pm 1.97$ & $6.33 \pm 1.78$ & $9.81 \pm 4.78$ & $<0.001$ \\
\hline NT-proBNP (pg/mL) & $863.13 \pm 2648.72$ & $1546.72 \pm 3747.96$ & $1621.95 \pm 3029.24$ & 0.153 \\
\hline hsCRP (mg/L) & $3.56 \pm 3.58$ & $4.24 \pm 3.93$ & $5.30 \pm 4.27$ & $<0.01$ \\
\hline $\mathrm{ACEI} / \mathrm{ARB}, n(\%)$ & $117(0.86)$ & $62(0.94)$ & $74(0.85)$ & 0.196 \\
\hline$\beta$-blocker, $n(\%)$ & $122(0.90)$ & $56(0.85)$ & $77(0.89)$ & 0.60 \\
\hline Statins, $n(\%)$ & $136(1.00)$ & $64(0.97)$ & $84(0.97)$ & 0.102 \\
\hline Gensini score & $49.66 \pm 41.10$ & $54.28 \pm 38.82$ & $62.19 \pm 42.96$ & 0.085 \\
\hline
\end{tabular}

HbAlc, glycosylatedhemoglobinAlc; DM, diabetes mellitus; MI, myocardial infarction; PCI, percutaneous coronary intervention; SBP, systolic blood pressure; DBP, diastolic blood pressure; HR, heart rate; LVEF, left ventricular ejection fraction; TC, total cholesterol; TG, triglycerides; HDL-C, high-density lipoprotein cholesterol; LDL-C, low-density lipoprotein cholesterol; ApoAl, apolipoprotein Al; ApoB, apolipoprotein B; Lp(a), lipoprotein (a); FBS, fasting blood sugar; hsCRP, high-sensitivity C-reactive protein; ACEI, angiotensin converting enzyme inhibition; ARB, angiotensin receptor blocker.

TABLE 2: Predictors of Gensini score: multivariate linear regression analysis.

\begin{tabular}{lccc}
\hline & Coefficient & $95 \%$ CI & $P$ \\
\hline logNT-proBNP & 11.24 & $1.86,20.63$ & $<0.05$ \\
ApoA1 & -79.78 & $-135.39,-24.16$ & $<0.01$ \\
LVEF & -0.56 & $-1.11,-0.01$ & $<0.05$ \\
HDL-C & 46.07 & $0.15,91.98$ & $<0.05$ \\
\hline
\end{tabular}

included the age, gender, smoking, diabetes, ventricular function, NT-proBNP, ApoA1, HDL-C, and fasting blood glucose. Notably, diabetic patients included those with previous history of diabetes and those with undiagnosed diabetes according to the new HbAlc cut-off points for diagnosis of diabetes [11]. Patients with $\mathrm{HbAlc}$ level $\geq 6.5 \%$ were diagnosed as diabetic, even without previous history of diabetes. HbAlc level was not associated with the risk of high Gensini score. This model demonstrated that diabetes and LVEF levels were two independent risk factors for high Gensini score: odds ratio (OR): 1.982, 95\% confidence interval (CI): 1.09, 3.59, $P<0.05$;
Table 3: Predictors of high Gensini score: multivariate logistic regression analysis.

\begin{tabular}{lcccc}
\hline Variables & Coefficient & OR & $95 \%$ CI & $P$ \\
\hline LVEF & -0.069 & 0.933 & $0.91,0.96$ & $<0.001$ \\
DM & 0.684 & 1.982 & $1.09,3.59$ & $<0.05$ \\
\hline
\end{tabular}

OR: $0.933,95 \%$ CI: $0.91,0.96, P<0.001$, respectively (Table 3).

\section{Discussion}

The present study aimed to evaluate the association of $\mathrm{HbAlc}$ level and the severity and extent of atherosclerotic lesion of coronary arteries in Chinese patients with ACS. The main finding of our study is that HbAlc level was not associated with the severity of CAD assessed by Gensini score in patients with ACS, even after adjustment for other related factors. However, we demonstrated that NT-proBNP, ApoAl, and LVEF levels were significant independent predictors for CAD severity. 
$\mathrm{HbAlc}$ has been used to monitor long-term glycemic control in diabetic patients and to diagnose DM [12]. Elevated $\mathrm{HbAlc}$ level was associated with the morbidity and mortality of cardiovascular disease in patients with or without DM, even when fasting glucose values were normal $[3,4]$. However, the prognostic value of HbAlc in patients with ACS remains controversial. Lazzeri et al. reported that $\mathrm{HbAlc}$ was not associated with the mortality in STEMI patients with known diabetes submitted to mechanical revascularization [13]. Cicek et al. showed that HbAlc was an independent predictor of the in-hospital mortality in STEMI patients treated with PCI after adjusting the baseline characteristics [14]. Timmer et al. found that elevated HbAlc level was associated with increased mortality rates over an average 3.3 years of follow-up in 4176 nondiabetic patients with STEMI submitted to PCI [5]. Liu et al. conducted a systematic review on patients hospitalized with CAD and did not detect a relationship between HbAlc level and mortality risk in diabetes [15].

The severity of coronary atherosclerosis is related to cardiovascular outcomes. Gensini score effectively reflects the severity of coronary stenoses and thus predicts the risk of cardiovascular events $[1,16]$. A combination of cardiovascular risk factors and Gensini score may provide valuable information on cardiovascular prognosis. However, our study revealed no significant correlation between HbAlc level and Gensini score by using a multiple linear regression model, suggesting that HbAlc level is not a major predictor for the extent of coronary atherosclerosis. Moreover, hsCRP level showed no significant association with CAD severity in the present study although it has been proposed as a prognostic factor for predicting major cardiovascular events and mortality [17]. Our results are consistent with a previous study by Ertem et al. who showed no significant relationship between HbAlc level and Gensini score in patients with ACS without DM [18]. To the best of our knowledge, no study has reported the relationship between HbAlc level and the severity of CAD evaluated with Gensini score in ACS patients with or without DM.

Several potential limitations of our study should be noted. First, the subjects in our study are exclusively limited to Chinese patients, so that conclusions should be drawn cautiously to other ethnic groups. Second, this retrospective study has a relatively small sample size from a single center. Therefore, it will be more powerful if a larger sample size is employed. Finally, intravascular ultrasonography (IVUS) may provide accurate information on atherosclerotic lesions, but no subjects in our study were evaluated by IVUS.

In conclusion, our data suggest that HbAlc level is not a significant and independent maker for the severity of angiography in ACS patients, even if in high-risk patients.

\section{Conflict of Interests}

The authors have no conflict of interests.

\section{Acknowledgment}

This study was supported by National Science Fund of China (no. 81273878).

\section{References}

[1] G. Huang, J.-L. Zhao, H. Du, X.-B. Lan, and Y.-H. Yin, "Coronary score adds prognostic information for patients with acute coronary syndrome," Circulation Journal, vol. 74, no. 3, pp. 490-495, 2010.

[2] D. R. McCance, R. L. Hanson, M.-A. Charles et al., "Comparison of tests for glycated haemoglobin and fasting and two hour plasma glucose concentrations as diagnostic methods for diabetes," British Medical Journal, vol. 308, no. 6940, pp. 1323-1328, 1994.

[3] M. Stolar, "Glycemic control and complications in type 2 diabetes mellitus," American Journal of Medicine, vol. 123, no. 3, pp. S3-S11, 2010.

[4] E. Selvin, M. W. Steffes, H. Zhu et al., "Glycated hemoglobin, diabetes, and cardiovascular risk in nondiabetic adults," The New England Journal of Medicine, vol. 362, no. 9, pp. 800-811, 2010.

[5] J. R. Timmer, M. Hoekstra, M. W. N. Nijsten et al., "Prognostic value of admission glycosylated hemoglobin and glucose in nondiabetic patients with ST-segment-elevation myocardial infarction treated with percutaneous coronary intervention," Circulation, vol. 124, no. 6, pp. 704-711, 2011.

[6] K.-T. Khaw, N. Wareham, R. Luben et al., "Glycated haemoglobin, diabetes, and mortality in men in Norfolk cohort of European Prospective Investigation of Cancer and Nutrition (EPIC-Norfolk)," British Medical Journal, vol. 322, no. 7277, pp. 15-18, 2001.

[7] C. Lazzeri, S. Valente, M. Chiostri, M. G. D’Alfonso, and G. F. Gensini, "Clinical significance of glycated hemoglobin inthe acute phase of ST elevation myocardial infarction," World Journal of Cardiology, vol. 4, pp. 140-147, 2014.

[8] E. W. Rebnord, E. R. Pedersen, E. Strand et al., "Glycated hemoglobin and long-term prognosis in patients with suspected stable angina pectoris without diabetes mellitus: a prospective cohort study," Atherosclerosis, vol. 240, no. 1, pp. 115-120, 2015.

[9] L.-F. Hong, X.-L. Li, Y.-L. Guo et al., "Glycosylated hemoglobin Alc as a marker predicting the severity of coronary artery disease and early outcome in patients with stable angina," Lipids in Health and Disease, vol. 13, no. 1, article 89, 2014.

[10] G. G. Gensini, "A more meaningful scoring system for determining the severity of coronary heart disease," The American Journal of Cardiology, vol. 51, no. 3, p. 606, 1983.

[11] B. Zinman, J. Gerich, J. B. Buse et al., "Standards of medical care in diabetes-2010," Diabetes Care, vol. 33, supplement 1, pp. S11S61, 2010, Erratum in: Diabetes Care, vol 33, p. 692, 2010.

[12] S. Inzucchi, R. Bergenstal, V. Fonseca et al., "Diagnosis and classification of diabetes mellitus," Diabetes Care, vol. 33, pp. S62-S69, 2010.

[13] C. Lazzeri, S. Valente, M. Chiostri, C. Picariello, P. Attanà, and G. F. Gensini, "The prognostic impact of glycated hemoglobin in diabetic ST-elevation myocardial infarction," International Journal of Cardiology, vol. 151, no. 2, pp. 250-252, 2011.

[14] G. Cicek, H. Uyarel, M. Ergelen et al., "Hemoglobin A1c as a prognostic marker in patients undergoing primary angioplasty for acute myocardial infarction," Coronary Artery Disease, vol. 22, no. 3, pp. 131-137, 2011.

[15] Y. Liu, Y.-M. Yang, J. Zhu, H.-Q. Tan, Y. Liang, and J.-D. Li, "Prognostic significance of hemoglobin Alc level in patients hospitalized with coronary artery disease. A systematic review and meta-analysis," Cardiovascular Diabetology, vol. 10, article 98, 2011. 
[16] C. Sinning, L. Lillpopp, S. Appelbaum et al., "Angiographic score assessment improves cardiovascular risk prediction: the clinical value of SYNTAX and gensini application," Clinical Research in Cardiology, vol. 102, no. 7, pp. 495-503, 2013.

[17] R. J. Bisoendial, S. M. Boekholdt, M. Vergeer, E. S. G. Stroes, and J. J. P. Kastelein, "C-reactive protein is a mediator of cardiovascular disease," European Heart Journal, vol. 31, no. 17, pp. 2087-2091, 2010.

[18] A. G. Ertem, H. Bağbanc1, H. Kiliç, E. Yeter, and R. Akdemir, "Relationship between HbAlc levels and coronary artery severity in nondiabetic acute coronary syndrome patients," Türk Kardiyoloji Derneği arşivi, vol. 41, no. 5, pp. 389-395, 2013. 


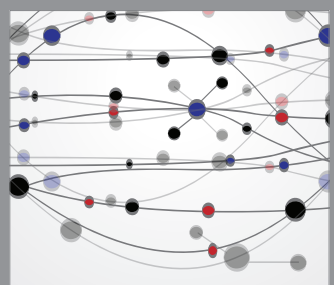

The Scientific World Journal
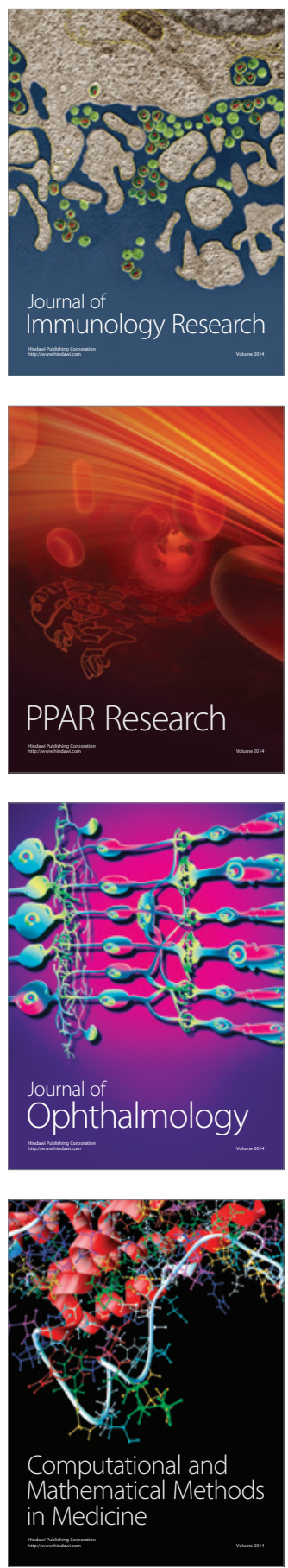

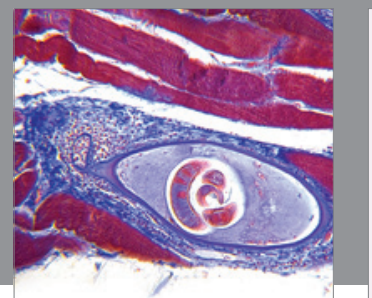

Gastroenterology

Research and Practice
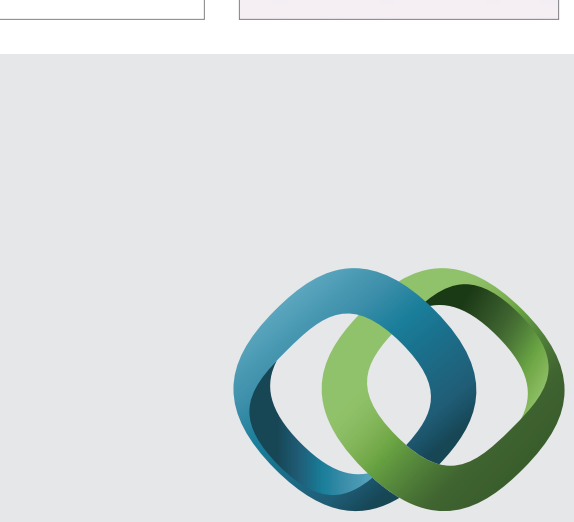

\section{Hindawi}

Submit your manuscripts at

http://www.hindawi.com
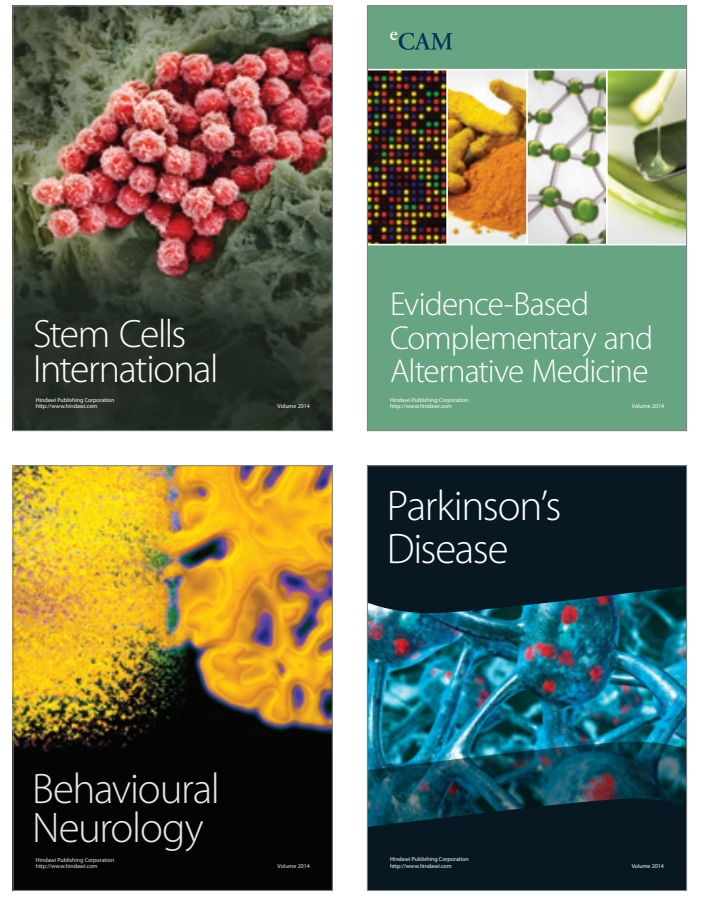
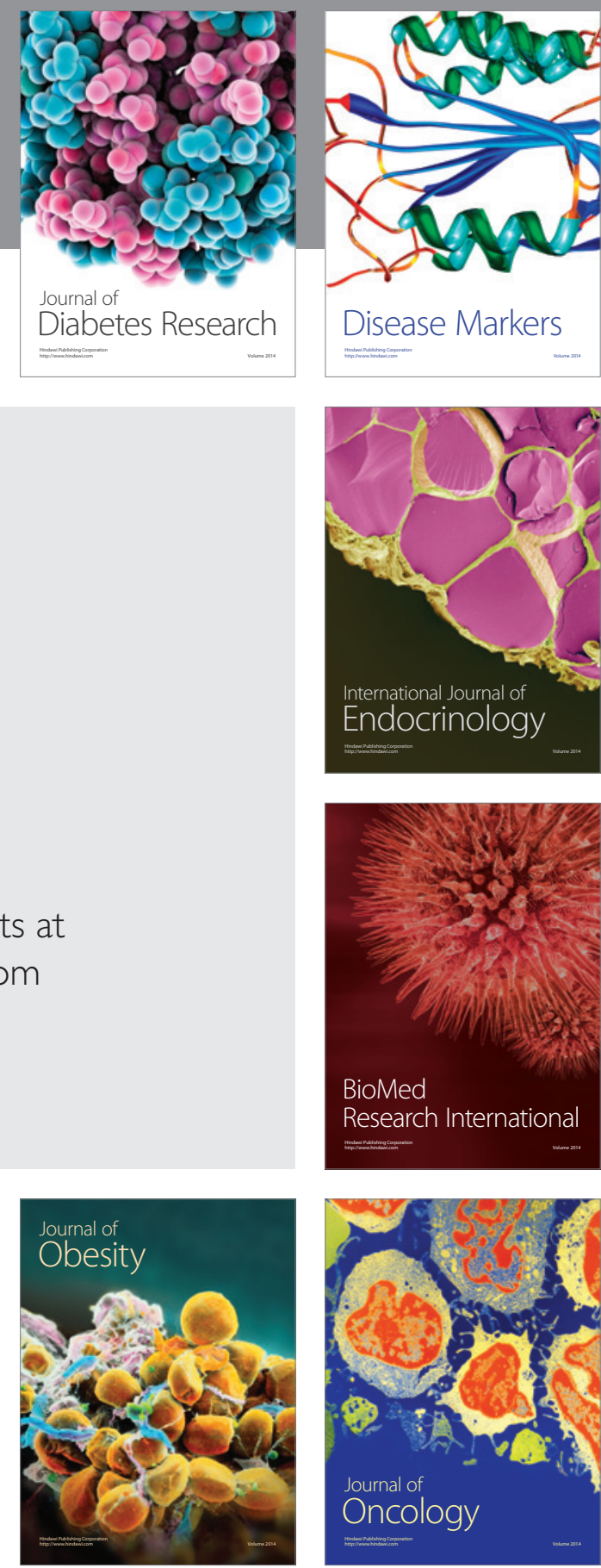

Disease Markers
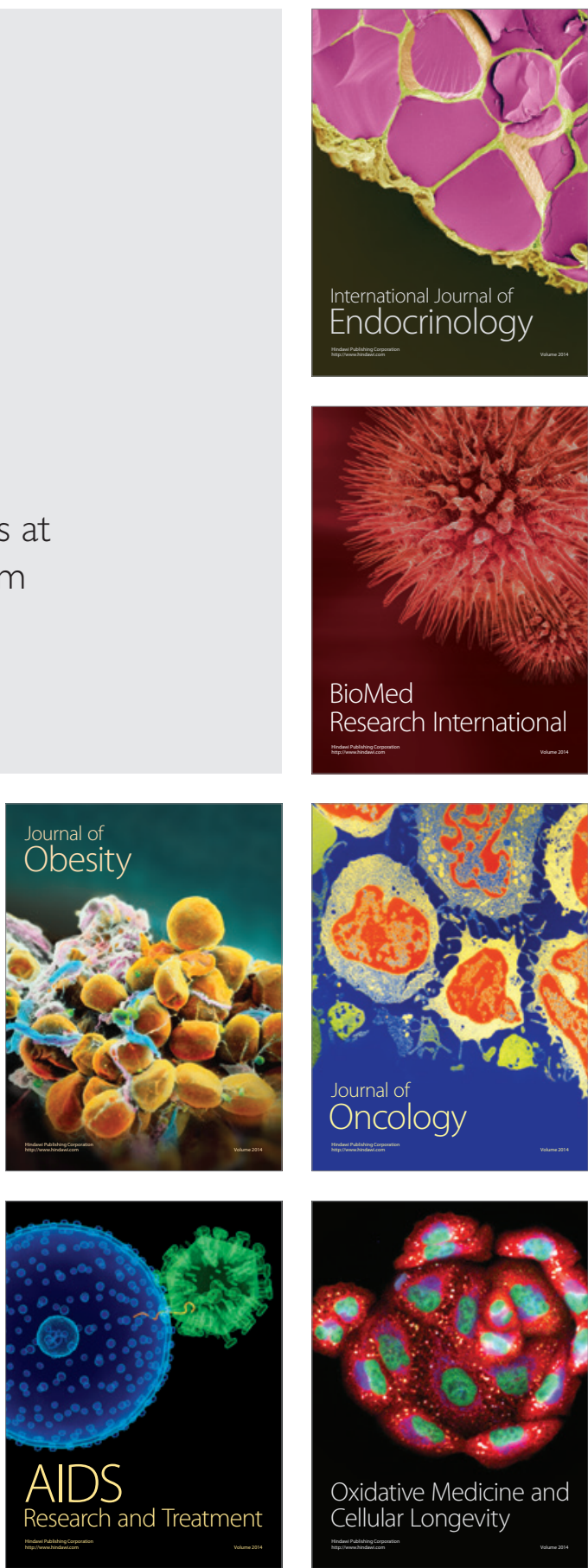